\title{
PROFIL DERMATITIS SEBOROIK DI POLIKLINIK KULIT DAN KELAMIN RSUP PROF. DR. R. D. KANDOU MANADO PERIODE JANUARI-DESEMBER 2012
}

\author{
${ }^{1}$ Ranita O. Terroe \\ ${ }^{2}$ Marlyn G. Kapantow \\ ${ }^{2}$ Renate T. Kandou \\ ${ }^{1}$ Kandidat skripsi Fakultas Kedokteran Universitas Sam Ratulangi \\ ${ }^{2}$ Bagian/SMF Kulit dan Kelamin RSUP Prof. Dr. R. D. Kandou Manado \\ Email: ranitaolivia@gmail.com
}

\begin{abstract}
Seborrheic dermatitis (SD) is a chronic, recurrent skin disease in areas which are abundant in sebaceous glands, with a prevalence of 3-5\% worldwide. Though its pathogenesis is still unknown, SD is related to sebum overproduction and the fungus Malassezia. SD can be suffered by all kinds of ages, most commonly found in men. The skin lesions found are erythematous, yellowish, oily squamas with uncircumscribed border. Pitiriasis sika, also known as dandruff, is a mild type of SD often suffered by people.This research is a retrospective descriptive study based on the number of cases, gender, age, location of lesion, and type of medication. Results shown that out of 134 seborrheic dermatitis cases (3,3\%), this disease is often suffered by the age group $45-65$ years old $(55,2 \%)$ and male $(67,2 \%)$, with most lesions located on the face $(53,7 \%)$ and with combined medication of corticosteroid + antifungal agent (62,7\%).
\end{abstract}

Keywords: seborrheic dermatitis

\begin{abstract}
Abstrak: Dermatitis seboroik (DS) adalah penyakit kulit kronis berulang pada area yang memiliki banyak kelenjar sebasea, dengan prevalensi 3-5\% di dunia. Patogenesis DS belum diketahui, namun DS memiliki hubungan terhadap produksi sebum yang berlebih dan adanya jamur Malassezia.DS dapat diderita oleh semua golongan umur, biasanya lebih sering diderita laki-laki.Kelainan kulit DS berwujud ritema dan skuama berminyak dan agak kekuningan dengan batas kurang tegas.Pitiriasis sika, atau ketombe, adalah jenis ringan DS yang paling sering diderita.Penelitian ini merupakan penelitian deskriptif retrospektif berdasarkan jumlah kasus, jenis kelamin, umur, lokasi lesi, dan jenis pengobatan.Hasil penelitian ini menunjukkan bahwa dari 134 kasus dermatitis seboroik (3,3\%), penyakit ini sering terjadi pada kelompok umur 45-65 tahun (55,2\%), jenis kelamin laki-laki (67,2\%), lokasi lesi wajah (53,7\%), dan pengobatan kombinasi topikal antara kortikosteroid + antijamur (62,7\%).
\end{abstract}

Kata kunci: dermatitis seboroik

Dermatitis seboroik adalah penyakit kulit kronis yang berulang dengan predileksi pada area yang memiliki banyak kelenjar sebasea. Walaupun patogenesis dari penyakit ini belum secara penuh dimengerti, dermatitis seboroik memiliki hubungan terhadap produksi sebum yang berlebih dan adanya Malassezia. ${ }^{1}$ Semua golongan umur, dari bayi sampai orang dewasa, dapat menderita dermatitis seboroik.Dermatitis seboroik pada bayi terjadi pada bulan-bulan pertama kehidupan, dan insidensnya mencapai puncak pada umur 18-40 tahun. Puncak kedua biasanya terjadi pada umur decade ke-4 sampai ke-7 kehidupan. ${ }^{2}$ Penyakit ini 
lebih sering diderita laki-laki daripada

Prevalensi dermatitis seboroik di dunia adalah 3-5\%. ${ }^{4}$ Di Amerika, data mengenai prevalensi dermatitis seboroik adalah sekitar $1-3 \%,{ }^{2}$ sedangkan data di RSUP Cipto Mangunkusumo Jakarta tahun 2000-2002 menunjukkan rata-rata prevalensi dermatitis seboroik $8,3 \%$ dari jumlah kunjungan. ${ }^{5}$ Riset di RSUP Prof. Dr. R. D. Kandou pada periode Januari 2005-Desember 2007 membuktikan bahwa dari 12,236 pasien yang datang ke Poliklinik Kulit dan Kelamin, didapatkan 267 pasien (2,18\%) dengan dermatitis seboroik. $^{6}$

Kelainan kulit pada dermatitis seboroik terdiri atas eritema dan skuama yang berminyak dan agak kekuningan, dengan batas kurang tegas.Bentuk dermatitis seboroik yang berat ditandai dengan adanya bercak-bercak yang berskuama dan berminyak disertai eksudasi dan krusta tebal. Sering meluas ke dahi, glabela, post auricular dan leher. ${ }^{7-8}$ Pada bentuk yang lebih berat lagi, seluruh kepala tertutup oleh krusta-krusta kotor, dan berbau tidak sedap, sehingga sangat berpengaruh terhadap kepercayaan diri penderita penyakit ini.

Pada bayi, skuama-skuama yang kekuningan pada kulit kepala disebut dengan cradle cap. Lesi-lesi dermatitis seboroik dapat terjadi juga pada daerah supraorbital, disertai dengan blefaritis, dan juga pada liang telinga luar, lipatan nasolabial, daerah sterna, aerola mammae, dan daerah lipatan-lipatan tubuh. ${ }^{2,9-10}$

Terapi yang diberikan pada pasien berbeda-beda, bergantung pada variasi morfologi dan respon terhadap pengobatan sebelumnya. Secara umum, terapi ditujukan untuk melepaskan, menghilangkan skuama dan krusta, menghambat kolonisasi ragi, mengontrol infeksi sekunder, serta mengurangi eritema dan gatal. ${ }^{4,12}$ Untuk penanganan secara topikal, obat-obatan yang biasa digunakan adalah krim ketokonazol, hidrokortison, primecrolimus, dan tacrolimus. Pada pitiriasis sika dapat digunakan shampoo yang mengandung selenium sulfide dan seng. Untuk penanganan dermatitis seboroik yang berat, dapat diberikan kortikosteroid secara oral, dosis prednisone 20-30 mg sehari. Bila terjadi perbaikan, dosis diturunkan secara perlahan-lahan.. ${ }^{6,9,13}$

Penelitian terakhir mengenai dermatitis seboroik di RSUP Prof. Dr. R. D. Kandou dilaksanakan pada tahun 2009.Diperlukan penelitian baru mengenai profil dermatitis seboroik di Poliklinik Kulit dan Kelamin RSUP Prof. Dr. R. D. Kandou pada tahun 2012.

\section{METODOLOGI PENELITIAN}

Penelitian ini merupakan penelitian deskriptif bersifat retrospektif dengan melihat dan mencatat kembali catatan rekam medik pasien dermatitis seboroik yang tercatat di Poliklinik Kulit dan Kelamin dan Instalasi Rekam Medik RSUP Prof. Dr. R. D. Kandou Manado periode Januari-Desember 2012. Populasi mencakup seluruh kasus yang tercatat menderita penyakit kulit di Poliklinik Kulit dan Kelamin RSUP Prof. Dr. R. D. Kandou Manado periode JanuariDesember 2012 dan sampel penelitian yaitu seluruh kasus yang tercatat menderita dermatitis seboroik. Variabel penelitian yaitu jumlah kasus, umur, jenis kelamin, lokasi lesi, dan jenis pengobatan.

\section{HASIL PENELITIAN}

Berdasarkan penelitian retrospektif di Poliklinik Kulit dan Kelamin serta Instalasi Rekam Medik BLU RSUP Prof. Dr. R. D. Kandou Manado tahun 2012, diperoleh data sebanyak 134 kasus (3,3\%) dari 4023 pasien yang berkunjung ke Poliklinik Kulit dan Kelamin.

Distribusi kasus dermatitis seboroik berdasarkan umur di RSUP Prof. Dr. R. D. Kandou Manado tahun 2012 didapatkan jumlah terbanyak pada golongan umur 4565 tahun sebanyak 74 kasus (55,2\%), dan diikuti golongan umur 25-44 tahun sebanyak 27 kasus (20,1\%). Golongan usia yang paling sedikit berada pada 
golongan umur 1 - 4 tahun sebanyak 1 kasus $(0,7 \%)$.

Tabel 1. Distribusi Kasus Dermatitis Seboroik Berdasarkan Jumlah Kasus di RSUP Prof. Dr. R. D. Kandou Manado Tahun 2012

\begin{tabular}{llll}
\hline & $\begin{array}{l}\text { Jumlah } \\
\text { seluruh }\end{array}$ & $\begin{array}{l}\text { Jumlah } \\
\text { kasus } \\
\text { Tahun }\end{array}$ & \\
& $\begin{array}{l}\text { kasus di } \\
\text { Poliklinik } \\
\text { Kulit \& } \\
\text { Kelamin }\end{array}$ & $\begin{array}{l}\text { seboroitis } \\
\text { seborin }\end{array}$ & \\
\hline 2012 & 4023 & 134 & $3,3 \%$
\end{tabular}

Tabel 2.Distribusi Kasus Dermatitis Seboroik Berdasarkan Umur

\begin{tabular}{ccc}
\hline Umur & $\begin{array}{c}\text { Jumlah } \\
\text { kasus }\end{array}$ & $\mathbf{\%}$ \\
\hline$<1$ & 2 & 1,5 \\
$1-4$ & 1 & 0,7 \\
$5-14$ & 3 & 2,2 \\
$15-24$ & 10 & 7,5 \\
$25-44$ & 27 & 20,1 \\
$45-65$ & 74 & 55,2 \\
$>65$ & 17 & 12,7 \\
\hline Total & $\mathbf{1 3 4}$ & $\mathbf{1 0 0 , 0}$ \\
\hline
\end{tabular}

Tabel 3.Distribusi Kasus Dermatitis Seboroik Berdasarkan Jenis Kelamin

\begin{tabular}{ccc}
\hline Jenis kelamin & $\begin{array}{c}\text { Jumlah } \\
\text { kasus }\end{array}$ & $\mathbf{\%}$ \\
\hline laki-laki & 90 & 67.2 \\
perempuan & 44 & 32.8 \\
\hline Total & $\mathbf{1 3 4}$ & $\mathbf{1 0 0 . 0}$ \\
\hline
\end{tabular}

Distribusi kasus dermatitis seboroik berdasarkan jenis kelamin di RSUP Prof. Dr. R. D. kandou Manado tahun 2012 didapatkan jumlah pasien laki-laki lebih banyak daripada pasien perempuan. Jumlah pasien laki-laki sebanyak 90 $(67,2 \%)$ sedangkan jumlah pasien perempuan sebanyak 44 (32,8\%).

Distribusi kasus dermatitis seboroik berdasarkan lokasi di RSUP Prof. Dr. R. D. Kandou Manado tahun 2012 didapatkan jumlah lokasi pada wajah adalah jumlah lokasi paling banyak yaitu 72 kasus (53,7\%). Kemudian lokasi pada wajah dan kepala adalah lokasi kedua terbanyak yaitu 38 kasus (28,4\%). Lokasi kombinasi adalah jumlah lokasi yang paling sedikit, yaitu 24 kasus (17,9\%).

Tabel 4.Distribusi Kasus Dermatitis Seboroik Berdasarkan Lokasi

\begin{tabular}{lll}
\hline Lokasi & Jumlah kasus & \% \\
\hline & & \\
Wajah & 72 & 53.7 \\
wajah, kepala & 38 & 28.4 \\
kombinasi & 24 & 17.9 \\
& & \\
\hline Total & $\mathbf{1 3 4}$ & $\mathbf{1 0 0 . 0}$ \\
\hline
\end{tabular}

Kombinasi: predileksi pada seluruh bagian tubuh

Tabel 5.Distribusi Kasus Dermatitis Seboroik Berdasarkan Jenis Pengobatan

\begin{tabular}{lll}
\hline Jenis pengobatan & $\begin{array}{l}\text { Jumlah } \\
\text { kasus }\end{array}$ & \% \\
\hline $\mathrm{KS}$ & 22 & 16.4 \\
$\mathrm{KS}+\mathrm{AJ}$ & 103 & 76.9 \\
$\mathrm{KS}+\mathrm{AJ}+\mathrm{AB}$ & 9 & 6.7 \\
\hline Total & $\mathbf{1 3 4}$ & $\mathbf{1 0 0 . 0}$ \\
\hline
\end{tabular}

KS: kortikosteroid topikal; AJ: antijamur topikal; AB: antibiotik topikal

Distribusi kasus dermatitis seboroik berdasarkan jenis pengobatan di RSUP Prof. Dr. R. D. Kandou tahun 2012 didapatkan pengobatan kombinasi antara kortikosteroid + anti jamur adalah pengobatan yang terbanyak yaitu 103 kasus (76,9\%). Kemudian, pengobatan dengan kortikosteroid adalah pengobatan terbanyak kedua dengan 22 kasus (16,4\%), dan pengobatan kombinasi antara kortikosteroid + antijamur + antibiotik adalah kombinasi pengobatan yang paling sedikit, yaitu sembilan kasus (6,7\%).

\section{BAHASAN}

Setelah dilakukan penelitian retrospektif di Poliklinik Kulit dan Kelamin serta Instalasi Rekam Medik 
RSUP Prof. Dr. R. D. Kandou Manado tahun 2012 didapatkan sebanyak 134 kasus dermatitis seboroik (3,3\%) dari 4035 pasien yang datang ke Poliklinik Kulit dan Kelamin. Jika dibandingkan dengan angka prevalensi pasien dermatitis seboroik periode 2005 - 2007 sejumlah $2,18 \%,{ }^{6}$ maka terlihat adanya kenaikan jumlah pasien dermatitis seboroik yang datang berkunjung memeriksakan diri ke Poliklinik Kulit dan Kelamin RSUP Prof. Dr. R. D. Kandou Manado. Walaupun demikian, angka tersebut masih jauh lebih rendah jika dibandingkan dengan angka insidens pasien dermatitis seboroik di RSUP Cipto Mangunkusumo Jakarta pada periode 2000 - 2002 yaitu 8,3\% dari jumlah kunjungan. ${ }^{5}$ Hal ini mungkin dikarenakan lebih sedikitnya jumlah pasien yang datang ke RSUP Prof. Dr. R. D. Kandou Manado daripada ke RSUP Cipto Mangunkusumo Jakarta atau penyimpanan rekam medis yang lebih lengkap di RSUP Cipto Mangunkusumo Jakarta.

Pada tabel 2, dapat dilihat bahwa golongan usia 45 - 65 tahun memiliki paling banyak kasus yaitu 74 (55,2\%), diikuti golongan usia 25 - 44 tahun yaitu 27 kasus (20,1\%), kemudian golongan usia $>65$ tahun dan 15 - 24 tahun masingmasing sebanyak 17 kasus (12,7\%) dan 10 kasus $(7,5 \%)$. Tidak jauh berbeda dengan penelitian yang dilakukan oleh Lalompoh selang tahun 2005 - 2007 di Poliklinik Kulit dan Kelamin RSUP Prof. Dr. R. D. Kandou Manado, didapatkan golongan umur yang paling sering menderita dermatitis seboroik adalah golongan usia $>$ 50 tahun. $^{6}$ Berdasarkan survey di Amerika, dermatitis seboroik paling sering terjadi pada usia 30 - 60 tahun yaitu dengan prevalensi $4,1 \%{ }^{12}$ Dikatakan bahwa insidens dermatitis seboroik mempunyai dua puncak, yang pertama pada bayi pada tiga bulan pertama kehidupan dan puncak yang kedua biasanya terjadi pada usia dekade ke $4-7$ kehidupan. $^{1-2,8-9}$ Insidens dermatitis seboroik yang tinggi pada bayi baru lahir berhubungan dengan ukuran dan aktivitas dari kelenjar sebasea. Hal tersebut bisa terjadi karena pada bayi mengalami produktivitas sebum sampai beberapa minggu setelah lahir, kemudian menjadi tidak aktif selama usia prapubertas. $^{1,8}$ Pada awal pubertas sampai dekade-dekade selanjutnya, aktivitas kelenjar sebasea mencapai puncak keduanya, sampai akhirnya menetap lebih lama pada laki-laki yaitu mencapai umur 50 - 60an, dan menurun pada perempuan akibat menopause. $^{8,11}$

Distribusi kasus dermatitis seboroik bedasarkan jenis kelamin pada tabel 3 didapatkan jumlah pasien laki-laki lebih banyak daripada pasien perempuan.Jumlah pasien laki-laki sebanyak 90 (67,2\%) sedangkan jumlah pasien perempuan sebanyak 44 (32,8\%). Demikian pula pada riset yang dilakukan oleh Lalompoh di RSUP Prof. Dr. R. D. Kandou lima tahun silam, laki-laki merupakan pasien dermatitis seboroik terbanyak yaitu 164 pasien (61,42\%), sedangkan perempuan sebanyak 103 pasien $(38,58 \%){ }^{6}$

Didapatkan pada tabel 4 wajah merupakan jumlah lokasi paling banyak yaitu 72 kasus (53,7\%). Kemudian predileksi pada wajah dan kepala adalah lokasi kedua terbanyak yaitu 38 kasus (28,4\%). Lokasi kombinasi adalah jumlah lokasi lesi yang paling sedikit, yaitu 24 kasus (17,9\%). Sesuai dengan kepustakaan, dermatitis seboroik memiliki lokasi pada daerah-daerah yang mengandung banyak kelenjar sebasea, yang salah satunya adalah wajah dan kulit kepala. $^{1-2,8,12}$

Pada tabel 5, jenis pengobatan dermatitis seboroik yang paling banyak diberikan terhadap pasien adalah kombinasi kortikosteroid topikal + antijamur topikal, yaitu 103 kasus (76,9\%). Kemudian, pengobatan dengan kortikosteroid topikal adalah pengobatan terbanyak kedua dengan 22 kasus (16,4\%), dan pengobatan kombinasi antara kortikosteroid topikal + antijamur topikal + antibiotik topikal adalah kombinasi pengobatan yang paling sedikit, yaitu 
sembilan kasus (6,7\%). Penggunaan kombinasi kortikosteroid topikal + antijamur topikal ini banyak dipilih karena tujuan dari pengobatan dermatitis seboroik yaitu menurunkan populasi jamur Malassezia, menurunkan dan mengeliminasi gejala inflamasi,dan mencegah rekurensi. Pada kasus dermatitis seboroik ringan, kulit biasanya sensitif terhadap krim kortikosteroid yang ringan. Pengobatan dengan tambahan antibiotik biasanya digunakan dengan dermatitis seboroik yang terinfeksi bakteri. ${ }^{2,8}$ Sama dengan penelitian yang dilakukan oleh Lalompoh tahun 2005 2007, pengobatan dermatitis seboroik terbanyak di Poliklinik Kulit dan Kelamin RSUP Prof. Dr. R D. Kandou adalah kombinasi kortikosteroid topikal + antijamur topikal yaitu 151 pasien $(56,55 \%){ }^{6}$

\section{SIMPULAN}

Dari hasil penelitian retrospektif di Poliklinik Kulit dan Kelamin serta Instalasi Rekam Medik RSUP Prof. Dr. R. D. Kandou Manado tahun 2012, dapat disimpulkan bahwa kasus dermatitis seboroik berjumlah 134 kasus (3,3\%) dari 4023 kasus. Kasus dermatitis seboroik paling banyak ditemukan pada golongan umur 45-65 tahun dan pada laki-laki daripada peremupan. Wajah merupakan lokasi lesi terbanyak, serta pengobatan yang terbanyak digunakan adalah kombinasi topikal antara kortikosteroid + antijamur.

\section{SARAN}

Agar memperoleh gambaran yang lebih baik dan jelas mengenai kasus dermatitis seboroik, perlu dilakukan pendataan yang lebih lengkap pada buku register dan rekam medik pasien, serta dijaga dengan baik.Akhirnya, diperlukan juga waktu yang lebih lama untuk dapat melaksanakan penelitian yang lebih komprehensif mengenai dermatitis seboroik.

\section{DAFTAR PUSTAKA}

1. Fritsch PO, Reider N. Other eczematous eruptions. In: Bolognia, Joziono, Rapini, editors. Dermatology. New York: Mosby Elsevier; 2008. p. 197-200.

2. Burns T, Breathnach S, Cox N, Griffiths C. Rook's Textbook of Dermatology. 8th ed. Chichester: Wiley-Blackwell; 2010.

3. Schwartz RA, Janusz CA, Janninger CK. Seborrheic dermatitis: an overview. American Family Physicians. 2006; 74.

4. Selden S, Travers $R$, Vinson $R$, Meffert J. [Medscape Reference].; 2014 [cited 2014 September 14. Available from: http://emedicine.medscape.com/ar ticle/1108312-

overview\#aw2aab6b2b3aa.

5. Kurniati DD. Dermatitis seboroik, gambaran klinis. In: Rihatmaja R, editor. Metode diganostik dan penalaksanaan psoriasis dan dermatitis seboroik. Jakarta: Balai Penerbit FKUI; 2003. p. 53-59.

6. Lalompoh BY. Profil Dermatitis seboroik di poliklinik kulit dan kelamin BLU RSUP Prof. R. D. Kandou Manado periode Januari 2005-Desember 2007 (Skripsi). Manado: Fakultas Kedokteran Universitas Sam Ratulangi; 2009.

7. DeAngelis YM, Gemmer CM, Kaczvinsky JR, Kenneally DC, Schwartz JR, Dawson TL. Three etiologic facets of dandruff and seborrheic dermatitis: Malassezia fungi, sebaceous lipids, and individual sensitivity. Journal of Invest Dermatol. 2005 December; 10.

8. Djuanda A, Hamzah $M$, Aisah $S$. Ilmu Penyakit Kulit \& Kelamin. 6th ed. Jakarta: Balai Penerbit FKUI; 2010.

9. Wolff K, Johnson RA, Suurmond D. Fitzpatrick's Color Atlas \& Synopsis of Clinical Dermatology. 5th ed.: The McGraw-Hill Companies; 2007.

10. Habif T. Clinical Dermatology: A 
Color Guide to Diagnosis and Therapy. 5th ed. Philadelphia: Elsevier Mosby; 2009.

11. Berk T, Scheinfeld N. Seborrheic dermatitis. Pharmacy \& Theurapetics. 2010 June; 35(6).

12. Naldi L, Rebora A. Seborreic dermatitis. NEJM 2009 January; 360.
13. Goldenberg G. Optimizing treatment approaches in seborrheic dermatitis. Journal of Clinical Aesthetic Dermatology. 2014 February; 6(2). 